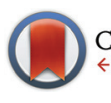

CrossMark $\leftarrow$ click for updates

Cite this: Dalton Trans., 2016, 45 3964

Received 19th October 2015, Accepted 19th January 2016

DOI: $10.1039 / c 5 d t 04107 d$

www.rsc.org/dalton

\title{
Platinum phosphinothiolato hydride complexes: synthesis, structure and evaluation as tin-free hydroformylation catalysts $\uparrow$
}

\author{
Julio Real, ${ }^{\star a}$ Esther Prat-Gil, ${ }^{a}$ Montserrat Pagès-Barenys, ${ }^{a}$ Alfonso Polo, ${ }^{b}$ \\ Joan F. Piniella ${ }^{c}$ and Ángel Álvarez-Larenac
}

\begin{abstract}
Ligand 2-diphenylphosphinothiophenol (Hsarp) reacted with $\mathrm{Pt}\left(\mathrm{PPh}_{3}\right)_{4}$ to yield trans-[PtH(sarp)(PPh 3$\left.)\right]$, which undergoes fast exchange with free $\mathrm{PPh}_{3}$ on the NMR time scale and very slowly and reversibly formed some cis-[PtH(sarp)(PPh $)$ ] over time in solution (11\%, 24 h). Reaction of trans-[PtH(sarp)(PPh $)$ ] with Hsarp in boiling toluene gave cis- and trans-[Pt(sarp $\left.)_{2}\right]$; the cis isomer being more stable. These complexes were characterized by ${ }^{1} \mathrm{H}$ and ${ }^{31} \mathrm{P} N M R$ and also analyzed by XRD in the case of trans- $[\mathrm{PtH}-$ (sarp) $\left.\left(\mathrm{PPh}_{3}\right)\right]$, trans-[Pt(sarp) $\left.)_{2}\right]$, and cis-[Pt(sarp) 2 . trans-[PtH(sarp)(PPh 3$\left.)\right]$ was evaluated as a preformed, tin-free hydroformylation catalyst on styrene and found active at $100{ }^{\circ} \mathrm{C}$, at pressures over 75 bar, yielding phenylpropanal (regioselectivities up to $83 \%$ in 2-phenylpropanal), with total conversions to aldehydes up to $100 \%$ at styrene/platinum ratios from $400 / 1$ to $1000 / 1$ and minimal hydrogenation products.
\end{abstract}

\section{Introduction}

Phosphinothiolato ligands behave as soft-soft chelates with very different donors in terms of size, electronic properties and Brønsted basicity. This difference makes phosphinothiolato-species unique heterotopic ligands. Transition metal complexes of sulfur-phosphorus ligands have been studied for their potential applications. ${ }^{1}$ The areas of interest include carbonylation $\quad$ reactions, ${ }^{2} \quad S$-alkylation $/ S$-dealkylation reactions, ${ }^{3}$ carbothiolations, ${ }^{4}$ and copolymerizations. ${ }^{5}$ These complexes are relevant in hydrodesulfurization (HDS), ${ }^{6}$ in the modeling of sulfur-containing metalloproteins ${ }^{7}$ and in imaging and radiotherapy. ${ }^{8}$

Olefin hydroformylation is a topic of continuing interest, ${ }^{9}$ including alternate metal catalysts (non-rhodium), which have been reviewed recently. ${ }^{10}$ The substitution of rhodium as the metal of choice for hydroformylation is not expected, but in some exceptional cases a third row metal (Ir) has been reported to outperform a second row metal (Rh) in catalytic carbonylation (see reports on the Cativa process). ${ }^{11}$

\footnotetext{
${ }^{a}$ Departament de Química, Universitat Autònoma de Barcelona, 08193 Bellaterra, Barcelona, Spain.E-mail:juli.real@uab.cat

${ }^{b}$ Departament de Quimica, Universitat de Girona. Campus de Montilivi, 17071 Girona, Spain

${ }^{c}$ Servei de Difracció de Raigs- $X$, Universitat Autònoma de Barcelona, 08193 Bellaterra, Barcelona, Spain

$\dagger$ Electronic supplementary information (ESI) available: NMR, IR spectra and crystal data. CCDC 1431425-1431427. For ESI and crystallographic data in CIF or other electronic format see DOI: $10.1039 / \mathrm{c} 5 \mathrm{dt} 04107 \mathrm{~d}$
}

As part of a project on the synthesis of new amino- and phosphino-thiolates of group 10 metals, and on the analysis of the ligand-based stereoelectronic effects that are determinant in their properties and potential applications, ${ }^{2 b, 12}$ we now report on platinum 2-diphenylphosphinothiophenolato complexes, their synthesis and structural features and the first tests as homogeneous, tin halide free hydroformylation catalysts. ${ }^{13}$

\section{Results and discussion}

\section{Synthetic aspects}

Ligand Hsarp (2-diphenylphosphinothiophenol) reacted with $\mathrm{Pt}\left(\mathrm{PPh}_{3}\right)_{4}$ to yield modest amounts of 1 (30\%) when used stoichiometrically (Scheme 1). When Hsarp was used in larger amounts the yield increased accordingly (up to 83\%); this is interpreted as a need to displace three moles of $\mathrm{PPh}_{3}$ from the sphere of coordination of platinum(0) to maximize the amount of platinum hydride formed before the addition of $\mathrm{Et}_{2} \mathrm{O}$ to precipitate 1 and to keep $\mathrm{PPh}_{3}$ in solution (Scheme 1).

The yield of $\mathbf{1}$ is only dependent on the excess of Hsarp, and is independent of the temperature or the reaction time, within reasonable limits. Crude $\mathbf{1}$ contains basically trans $\mathbf{- 1}$ with small amounts of free $\mathrm{PPh}_{3}$ (ca. 0.5-1\%). Crude 1 could be further purified by column chromatography on silica or by slow recrystallization to obtain pure trans-1. Solutions of trans-1 are stable to decomposition but evolve to an equilibrium mixture of trans-1 (89\%) and cis-1 (11\%) isomers, which is complete in $24 \mathrm{~h}$. 


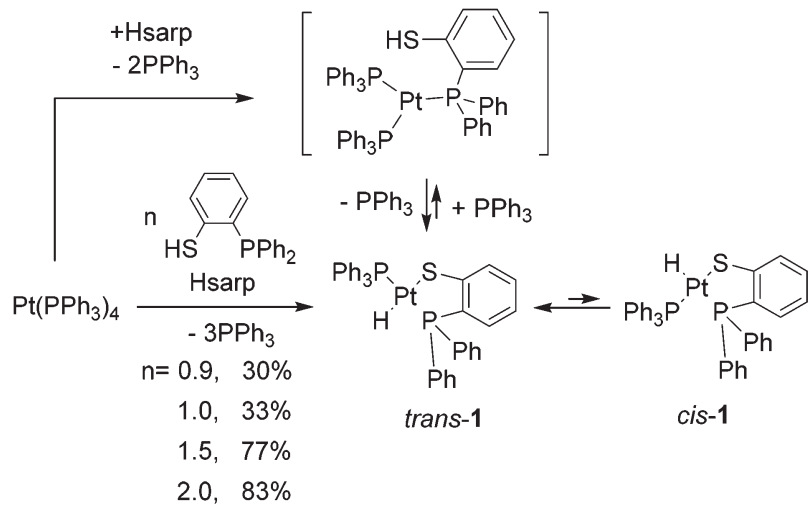

Scheme 1 Synthesis of $\left[\mathrm{PtH}(\operatorname{sarp}) \mathrm{PPh}_{3}\right], n$ is the Hsarp/Pt ratio used.

Upon heating Hsarp with $\mathrm{Pt}\left(\mathrm{PPh}_{3}\right)_{4}$ or trans-1 in toluene at $110^{\circ} \mathrm{C}$, the platinum hydride was observed to decrease in concentration with time, until all the hydride turned into cis-[Pt(sarp) $)_{2}$ (cis-2). A complete reaction takes $28 \mathrm{~h}$; if the reaction is stopped before completion, the corresponding amounts of $\mathbf{1}$ and $\mathbf{2}$ can be recovered without much loss, which demonstrates the remarkable thermal stability of hydride $\mathbf{1}$. We envision this reaction as two step: the fast substitution of $\mathrm{PPh}_{3}$ by Hsarp and the slow reaction of platinum hydride with $-\mathrm{SH}$, to give hydrogen (Scheme 2). Furthermore, in a similar addition involving $\mathrm{HSCH}_{2} \mathrm{CH}_{2} \mathrm{PPh}_{2}$ (dppet), this has been found to be the rate-determining step, according to conceptual DFT calculations. ${ }^{14}$

$$
\text { trans-1 }
$$

Scheme 2

The bischelate obtained in this way may contain small amounts of trans-[Pt(sarp $\left.)_{2}\right]$ which can be converted to cis$\left[\mathrm{Pt}(\operatorname{sarp})_{2}\right]$ by further heating at $110{ }^{\circ} \mathrm{C}$ in toluene. The greater thermodynamic stability of the cis isomer is predicted by the greater trans influence of phosphorous over sulfur (or by the so called antisymbiosis rule $)^{15}$ while steric hindrance would favour the trans isomer. In the case of palladium, we have shown that trans and cis bischelates $\left[\operatorname{Pd}(\operatorname{sarp})_{2}\right]$ interconvert in solution and the equilibrium can be displaced towards the former or the latter by the use of polar or non-polar crystallization solvents respectively. ${ }^{16}$ In the case of platinum this procedure proved impractical, as trans-2 does not form in sufficient amounts in any solvent tested in reasonable reaction times. Bischelate cis-2 is also the identifiable platinum product of the thermal decomposition of $\mathbf{1}$ in boiling toluene.

The bulkier ligand, 2-diphenylphosphino-6-trimethylsililthiophenol (Hsarp'), reacted in the same way as Hsarp to yield the corresponding hydride $\left[\mathrm{PtH}\left(\mathrm{sarp}^{\prime}\right)\left(\mathrm{PPh}_{3}\right)\right]$<smiles>CSc1cccc2c1SP(Pc1ccccc1)[PH]2(c1ccccc1)c1ccccc1</smiles>

3<smiles>CCS1([PH])SCC[PbH]1</smiles>

4

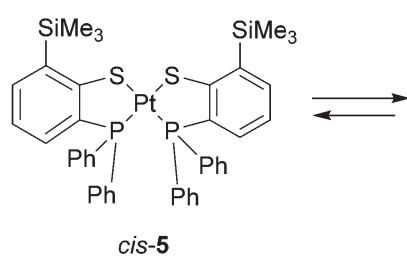

Scheme 3<smiles>CCS1([PH])SCC[Pb]1</smiles><smiles>CCS1(P)SCC[PH]1c1ccccc1</smiles>

not detected

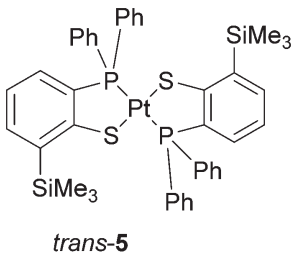

trans-5
(Scheme 3). For comparison purposes, the ligand EtSCH${ }_{2} \mathrm{CH}_{2} \mathrm{SH}$ was also prepared and used in the synthesis of $\left[\mathrm{PtH}\left(\mathrm{EtSCH}_{2} \mathrm{CH}_{2} \mathrm{~S}-\kappa^{2} S, S\right)\left(\mathrm{PPh}_{3}\right)\right]$, which was made from $\mathrm{Pt}\left(\mathrm{PPh}_{3}\right)_{4}$ in the same way as $\mathbf{1}$ and 3 , but by using a stoichiometric amount of the ligand. ${ }^{17}$ At room temperature, fast exchange was not observed in the NMR of $\mathbf{4}$ and isomerization was not detected (Scheme 3).

The reaction of Hsarp' with $\mathrm{Pt}\left(\mathrm{PPh}_{3}\right)_{4}$ in boiling toluene gave the bischelates $\mathbf{5}$, with the difference compared to $\mathbf{2}$, that a longer time ( $48 \mathrm{~h}$ ) was needed for the bulkier ligand and the product was a mixture of cis and trans isomers, containing a slight excess of the latter (Scheme 3). Clearly, in the case of sarp' the trans isomer becomes more stable for steric reasons.

\section{NMR spectroscopy}

The hydride region of the ${ }^{1} \mathrm{H}$ NMR spectra of crude 1 consisted of a doublet with ${ }^{195} \mathrm{Pt}$ satellites and the ${ }^{31} \mathrm{P}$ NMR showed just noise at room temperature. This was attributed to the exchange phenomena, so the NMR were taken at low temperature (down to $-60^{\circ} \mathrm{C}$ ) but the slow exchange limit was not achieved in this way. Purification of $\mathbf{1}$ by chromatography or recrystallization gave samples free of $\mathrm{PPh}_{3}$ which exhibited non-exchanging, narrow lined ${ }^{1} \mathrm{H}$ and ${ }^{31} \mathrm{P}$ NMR spectra. The obvious conclusion is that exchange takes place between $\mathbf{1}$ and free $\mathrm{PPh}_{3}$ and this is a bimolecular reaction that cannot proceed in the absence of $\mathrm{PPh}_{3}$. The long accumulation of ${ }^{31} \mathrm{P}$ NMR spectra on samples of crude 1 at room temperature showed the NMR of Fig. 1, which consists of the very broad signals of trans-1, which exchanges with free $\mathrm{PPh}_{3}$, and very small amounts of cis-1 and cis-2 (narrow lines).

Relevant NMR data are collected in Tables 1 and 2. Hydride signals are well shifted to low frequencies into negative delta values. Hydride coupling to platinum $\left({ }^{1} J_{\mathrm{PtH}}\right)$ is typically very large and it is observed in all cases. Coupling to the sarp 


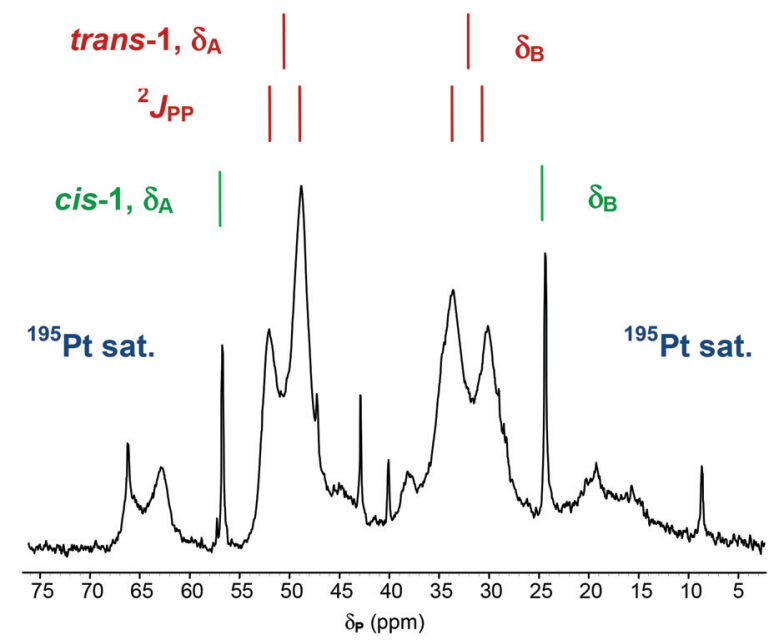

Fig. 1 Long time accumulation ${ }^{31} \mathrm{P}\left\{{ }^{1} \mathrm{H}\right\} \mathrm{NMR}$ (101 $\mathrm{MHz}, \mathrm{CD}_{2} \mathrm{Cl}_{2}$, rt) spectrum of crude 1 ( $22 \mathrm{~K}$ transients), the broad signals correspond to trans-1 (the major product, red marks) and the narrow ones to cis-1 (green marks), the broadness is caused by exchange of trans-1 with trace amounts of free $\mathrm{PPh}_{3}$ (estimated at ca. $\left.0.5 \%\right) ;{ }^{195} \mathrm{Pt}(33.8 \%$ abundance) satellites are observable. The signal at $\delta 43$ corresponds to a small amount of cis-[Pt(sarp) $)_{2}$.

Table 1 Hydrido ligand ${ }^{1} \mathrm{H}$ NMR spectroscopic data for platinum(॥) complexes $^{a}$

\begin{tabular}{lcclc}
\hline Complex & $\delta(\mathrm{H}-\mathrm{Pt})$ & $J(\mathrm{H}-\mathrm{Pt})$ & $J\left(\mathrm{H}-\mathrm{P}_{\mathrm{A}}\right)$ & $J\left(\mathrm{H}-\mathrm{P}_{\mathrm{B}}\right)$ \\
\hline trans-1 & $-7.61 \mathrm{dd}$ & 1022 & 8.1 & 19.8 \\
cis-1 & $-4.77 \mathrm{dd}$ & 950 & 186 & 9.9 \\
trans $-\mathbf{1}+\mathrm{PPh}_{3}$ & $-7.57 \mathrm{~d}$ & 1023 & 8.0 & - \\
trans-3 $+\mathrm{PPh}_{3}$ & $-7.08 \mathrm{~d}$ & 1151 & 6.6 & - \\
$\mathbf{4}$ & $-10.63 \mathrm{~d}$ & 1206 & - & 20.0
\end{tabular}

${ }^{a}$ Chemical shifts on the $\delta$ scale, coupling constants in Hz. $\mathrm{P}_{\mathrm{A}}$ values are assigned to the phosphinothiolato ligand and $\mathrm{P}_{\mathrm{B}}$ values to $\mathrm{PPh}_{3}$. All spectra were recorded in $\mathrm{CD}_{2} \mathrm{Cl}_{2}$ at $\mathrm{rt}(298 \mathrm{~K})$, signals have ${ }^{195} \mathrm{Pt}$ satellites of correct intensity for mononuclear complexes at natural abundance.

Table $2{ }^{31} \mathrm{P}\left\{{ }^{1} \mathrm{H}\right\}$ NMR data for platinum(II) complexes ${ }^{a}$

\begin{tabular}{llllll}
\hline Complex & $\delta \mathrm{P}_{\mathrm{A}}$ & $J\left(\mathrm{P}_{\mathrm{A}}-\mathrm{Pt}\right)$ & $\delta \mathrm{P}_{\mathrm{B}}$ & $J\left(\mathrm{P}_{\mathrm{B}}-\mathrm{Pt}\right)$ & $J\left(\mathrm{P}_{\mathrm{A}}-\mathrm{P}_{\mathrm{B}}\right)$ \\
\hline trans-1 & $50.5 \mathrm{~d}$ & 2819 & 31.9 & 2915 & 391.2 \\
cis-1 & $56.6 \mathrm{~d}$ & 1922 & 24.3 & 3187 & 10.1 \\
trans-1 $+\mathrm{PPh}_{3}$ & $50.5 \mathrm{~s}$ & 2801 & - & - & - \\
trans-3 $\mathrm{PPh}_{3}$ & $48.2 \mathrm{~s}$ & 2990 & - & - & - \\
$\mathbf{4}$ & & & 23.7 & 3215 & \\
cis-2 & $42.8 \mathrm{~S}$ & 2912 & & & \\
trans-2 & $50.8 \mathrm{~S}$ & 2645 & & & \\
cis-5 & $41.9 \mathrm{~S}$ & 2867 & & & \\
trans-5 & $48.9 \mathrm{~S}$ & 2629 & & & \\
& & & &
\end{tabular}

${ }^{a}$ Chemical shifts on the $\delta$ scale, coupling constants in $\mathrm{Hz} . \mathrm{P}_{\mathrm{A}}$ values are assigned to the phosphinothiolato ligands and $\mathrm{P}_{\mathrm{B}}$ values to $\mathrm{PPh}_{3}$. All spectra were recorded in $\mathrm{CD}_{2} \mathrm{Cl}_{2}$ at $\mathrm{rt}(298 \mathrm{~K})$, signals have ${ }^{195} \mathrm{Pt}$ satellites of correct intensity for mononuclear complexes at natural abundance. phosphorus $\left({ }^{2} J_{\mathrm{PH}}, \mathrm{P}_{\mathrm{A}}\right)$ is also observed in fast exchange and no exchange conditions, while coupling to the $\mathrm{PPh}_{3}$ phosphorus $\left({ }^{2} J_{\mathrm{PH}}, \mathrm{P}_{\mathrm{B}}\right)$ is only observed in the absence of free $\mathrm{PPh}_{3}$, that is, in the absence of exchange. In this case the spectra have been obtained from samples that contained minute amounts of free $\mathrm{PPh}_{3}$ (see Tables 1 and 2). Complex 4 showed no such exchange with added $\mathrm{PPh}_{3}$ at room temperature, so that, we conclude that the exchange is directly related to the trans effect of the phosphorus of the sarp ligand.

${ }^{31} \mathrm{P}$ NMR mirrors in most ways the results observed in ${ }^{1} \mathrm{H}$ NMR. In the absence of free $\mathrm{PPh}_{3}$, the resonances of 1 are narrow and all $\delta$ and $J$ can be assigned. In the presence of $\mathrm{PPh}_{3}$ (the fast exchange limit) only the chelate ligand phosphorus is observed, including its coupling to platinum $\left(J_{\mathrm{PtP}}, \mathrm{P}_{\mathrm{A}}\right)$ but not to $\mathrm{PPh}_{3}$ phosphorus $\left(\mathrm{P}_{\mathrm{B}}\right)$.

The effect of free $\mathrm{PPh}_{3}$ on the NMR of trans-1 was better understood by recording the ${ }^{31} \mathrm{P}$ NMR spectra of a sample of trans-1 after adding known amounts of free $\mathrm{PPh}_{3}$ in an NMR titration-like experiment (Fig. 2). The addition of just $0.5 \mathrm{~mol} \%$ $\mathrm{PPh}_{3}$ to pure trans-1 caused immediate collapse of the ${ }^{31} \mathrm{P}$ signals; at $5 \%$ the signal corresponding to $\mathrm{P}_{\mathrm{A}}$ started to rise (broad), at about $50 \%$ the signal of $\mathrm{P}_{\mathrm{A}}$ (with ${ }^{195} \mathrm{Pt}$ satellites) was narrower and the signal of free $\mathrm{PPh}_{3}$ started to rise from the noise (broad), at $300 \%$ the exchange was fast enough for the $\mathrm{PPh}_{3}$ to be quite narrow, but clearly displaced down-field from the known chemical shift of $\mathrm{PPh}_{3}$. To see cis-1 in the NMR spectrum, solutions of trans-1 were allowed to age. After $24 \mathrm{~h}$ equilibrium was reached at room temperature; the equilibrium mixture in dichloromethane solution contained both trans-1 $(89 \%)$ and cis-1 (11\%), but crystallization from $\mathrm{CH}_{2} \mathrm{Cl}_{2} /$ $\mathrm{Et}_{2} \mathrm{O}$ yielded only trans-1. The thermodynamic stability of the trans- $P, P$ isomer is in agreement with the high trans influence of hydride, in contrast with the low trans influence of chloride which gives $c i s-P, P-\left[\mathrm{PtCl}\left(\right.\right.$ dppet- $\left.\left.^{2} P, S\right) \mathrm{PPh}_{3}\right] .^{7 a}$

Coupling constants were useful in the characterization of these compounds. ${ }^{18}$ The ${ }^{2} J_{\mathrm{PH}}$ coupling constant in cis-1 is much larger $(186 \mathrm{~Hz})$ than any other $J_{\mathrm{PH}}$ because this is the only case in which the hydride ligand is trans to phosphorus (Table 1). In the case of phosphorus to phosphorus, ${ }^{2} J_{\mathrm{PP}}$ is much larger in trans-1 $(391 \mathrm{~Hz})$ than in cis-1 $(10.1 \mathrm{~Hz})$. Coupling to platinum is strong both for ${ }^{1} \mathrm{H}$ and ${ }^{31} \mathrm{P}$, but much larger ${ }^{1} J_{\mathrm{PtP}}$ coupling constants are expected for $c i s-P, P$ isomers than for trans- $P, P$ isomers, this criterion has been followed to assign the signals of trans-2 and cis-2 (Table 2), which was supported by the XRD studies (vide infra). However, coupling of the sarp phosphorus to platinum ${ }^{1} J_{\mathrm{PtP}}$ is comparatively small in cis-1 (Table 2), this is most probably caused by the strong trans influence of the hydride ligand. There are numerous precedents of this effect: in cis-[ $\left.\mathrm{PtH}_{2}\left(\mathrm{PEt}_{3}\right)_{2}\right],{ }_{\mathrm{PtP}}^{1}=1984 \mathrm{~Hz}$, while in trans- $\left[\mathrm{PtH}_{2}\left(\mathrm{PEt}_{3}\right)_{2}\right],{ }^{1} J_{\mathrm{PtP}}=2764 \mathrm{~Hz}$; and in cis- $\left[\mathrm{PtH}_{2}\left(\mathrm{PMe}_{3}\right)_{2}\right]$, ${ }^{1} J_{\mathrm{PtP}}=1875 \mathrm{~Hz}$, while in trans $-\left[\mathrm{PtH}_{2}\left(\mathrm{PMe}_{3}\right)_{2}\right],{ }^{1} J_{\mathrm{PtP}}=2594$ Hz. ${ }^{19 a, b}$ Complexes cis- $\left[\mathrm{PtR}_{2} \mathrm{~L}_{2}\right]\left(\mathrm{R}=\right.$ alkyl ${ }^{19 c}$ aryl $;{ }^{19 d} \mathrm{~L}=\mathrm{PPh}_{3}$, $\left.\mathrm{PMe}_{3}, \mathrm{PEt}_{3}\right)$ also feature comparatively small ${ }^{1}{ }_{\mathrm{PtP}}$.

The behavior of $\mathbf{1}$ in solution is summarized in Scheme 4 . The first reaction represents the fast exchange we observe in the NMR. Platinum(II) will form a more stable trigonal bipyra- 


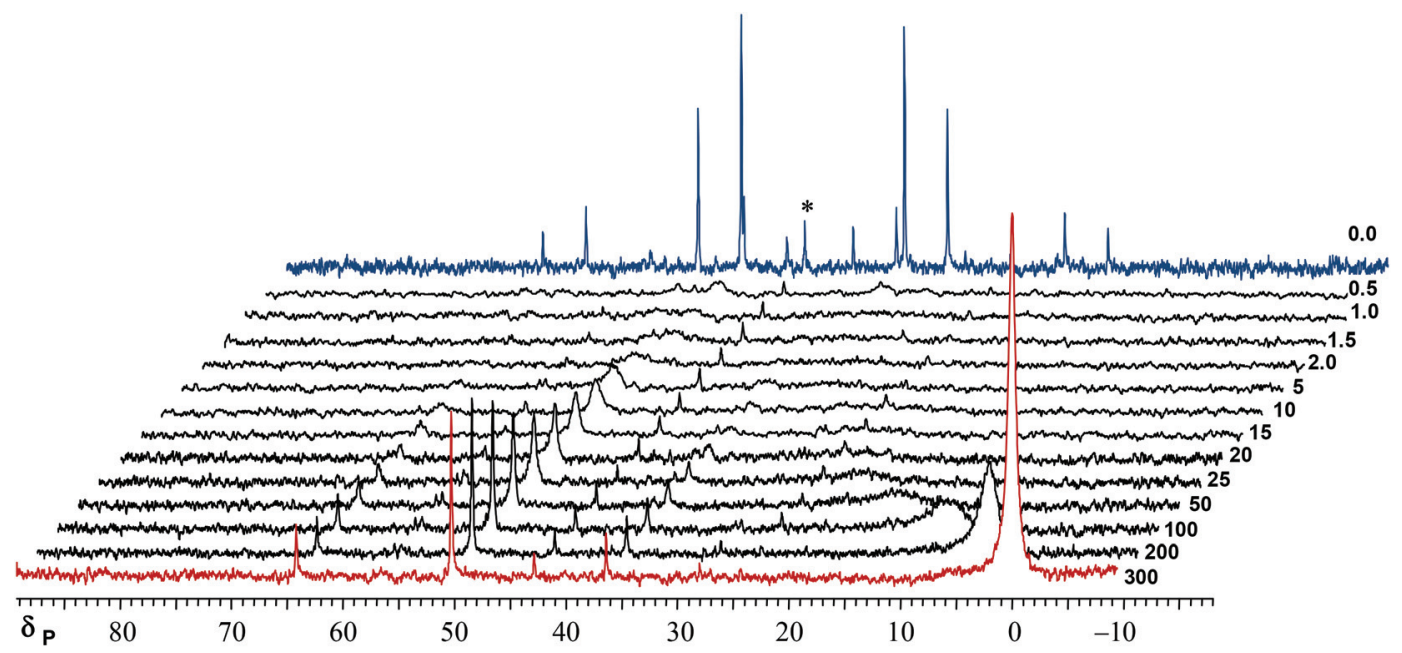

Fig. 2 The addition of free $\mathrm{PPh}_{3}$ to a sample of pure trans-1 (uppermost trace) caused a dramatic change in its ${ }^{31} \mathrm{P}\left\{{ }^{1} \mathrm{H}\right\} \mathrm{NMR}$ spectrum $(101 \mathrm{MHz}$, $\left.\mathrm{CD}_{2} \mathrm{Cl}_{2}, \mathrm{rt}\right)$, the added amounts are indicated by the traces in mol\% of added $\mathrm{PPh}_{3}$. A small amount of cis-[Pt(sarp) $\left.)_{2}\right]$ was added for reference $(*)$.

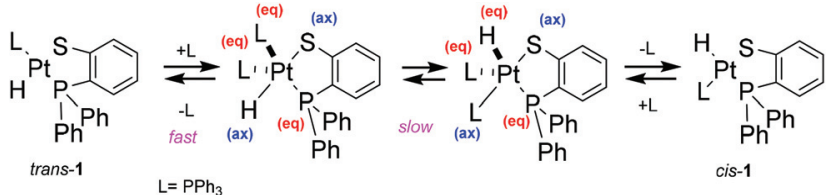

Scheme 4 Proposed mechanism of ligand exchange. On the NMR time scale exchange with free $L$ is fast for trans-1; conversely, the ligand rearrangement $\left(H_{a x}\right.$ to $H_{e q}$ and $L_{e q}$ to $\left.L_{a x}\right)$ that gives rise to cis-1 is understandably slow.

midal (tbp) intermediate with the bulky phosphorus ligands in equatorial (eq) positions and with the sarp chelate bonding in an axial-equatorial fashion. To form cis-1, the tbp intermediate must rearrange to a less favourable intermediate (in Scheme 4 this is depicted by $\mathrm{L}$ in an axial position), and this is presumably the reason why trans/cis isomerisation is such a slow process for 1.

In the exchange process of trans-1 we believe that sarp remains coordinated in the $\mathrm{S}_{\mathrm{ax}}-\mathrm{P}_{\mathrm{eq}}$ mode, supported by the fact that the chemical shift of $\mathrm{P}_{\mathrm{A}}$ is the same in the fast exchange limit and the no exchange (slow exchange) limit. The chemical shift of ${ }^{31} \mathrm{P}$ is strongly affected by the formation of cycles and any opening of the chelate should affect the $\delta_{\mathrm{P}}$ of $\mathrm{P}_{\mathrm{A}}$. The coupling of $\mathrm{P}_{\mathrm{A}}$ to platinum is also retained in the fast exchange limit (Fig. 2).

\section{XRD crystal structures}

Slow crystallization of $\mathbf{1}$ gave yellow crystals of trans-1 exclusively; crystals of minor isomer cis-1 could not be obtained from normal laboratory solvents. Crystallization of 2 in $\mathrm{CH}_{2} \mathrm{Cl}_{2} / \mathrm{Et}_{2} \mathrm{O}$ gave mainly chunky yellow crystals of cis2. $\mathrm{CH}_{2} \mathrm{Cl}_{2}$, which is isostructural with the palladium complex cis- $\left[\mathrm{Pd}(\mathrm{sarp})_{2}\right] \cdot \mathrm{CH}_{2} \mathrm{Cl}_{2} \cdot{ }^{16}$ However, careful inspection revealed the presence of a few smaller crystals of a more intense colour and an apparently different habit, which upon XRD analysis proved to be trans-2.

The structures exhibit slightly distorted square planar platinum(II) coordination. In the case of trans-1 (Fig. 3) it is worth noting the relatively long $\mathrm{Pt}-\mathrm{S}$ distance (Table 3 ), which is ascribed to the strong trans influence of hydride. The chelate angle of sarp (Table 3 ) is always about $87^{\circ}$, as it is a rigid ligand. This angle makes sarp a well suited ligand both for cis coordination in sqp structures and for $\mathrm{S}_{\mathrm{ax}}-\mathrm{P}_{\mathrm{eq}}$ coordination in tbp intermediates, which are stabilized by the nature of sarp in terms of the bite angle and size of the coordinating groups (see above, Scheme 4).

Table 3 Relevant distances $(\AA)$ and angles $\left({ }^{\circ}\right)$ for trans-1, trans-2 and cis-2, obtained in this work

\begin{tabular}{|c|c|c|c|c|c|}
\hline \multicolumn{2}{|l|}{ trans $\mathbf{- 1}$} & \multicolumn{2}{|l|}{ trans-2 } & \multicolumn{2}{|c|}{ cis-2. $\mathrm{CH}_{2} \mathrm{Cl}_{2}$} \\
\hline Pt-S & $2.357(3)$ & Pt-S & $2.315(2)$ & Pt-S1 & $2.313(5)$ \\
\hline Pt-P1 & $2.243(3)$ & Pt-P & $2.293(2)$ & $\mathrm{Pt}-\mathrm{S} 2$ & $2.326(4)$ \\
\hline $\mathrm{Pt}-\mathrm{P} 2$ & $2.278(3)$ & & & $\begin{array}{l}\mathrm{Pt}-\mathrm{P} 1 \\
\mathrm{Pt}-\mathrm{P} 2\end{array}$ & $\begin{array}{l}2.263(4) \\
2.249(4)\end{array}$ \\
\hline $\mathrm{S}-\mathrm{Pt}-\mathrm{P} 1^{a}$ & $86.9(1)$ & $\mathrm{S}-\mathrm{Pt}-\mathrm{P}^{a}$ & $86.96(7)$ & $\mathrm{S} 1-\mathrm{Pt}-\mathrm{P} 1^{c}$ & $87.7(2)$ \\
\hline $\mathrm{S}-\mathrm{Pt}-\mathrm{P} 2$ & $98.6(1)$ & $\mathrm{S}^{\prime}-\mathrm{Pt}-\mathrm{P}^{b}$ & $93.04(7)$ & $\mathrm{S} 2-\mathrm{Pt}-\mathrm{P} 2^{c}$ & $87.4(2)$ \\
\hline P1-Pt-P2 & 171.6(1) & $\mathrm{Pt}-\mathrm{S}-\mathrm{C} 2$ & $105.7(2)$ & $\mathrm{S} 1-\mathrm{Pt}-\mathrm{S} 2$ & $84.7(2)$ \\
\hline Pt-S-C1 & 104.6(3) & $\mathrm{Pt}-\mathrm{P}-\mathrm{C} 1$ & $107.5(2)$ & P1-Pt-P2 & $100.3(2)$ \\
\hline $\mathrm{Pt}-\mathrm{P} 1-\mathrm{C} 2$ & 109.1(3) & & & S1-Pt-P2 & $172.0(2)$ \\
\hline & & & & S2-Pt-P1 & $171.7(2)$ \\
\hline
\end{tabular}

${ }^{a}$ Chelate angle. ${ }^{b}$ Open angle, platinum is at the inversion center, $\mathrm{S}^{\prime}$ is related to $\mathrm{S}$ by $-x,-y,-z .{ }^{c}$ Chelate angle, $\mathrm{S} 1$ and $\mathrm{P} 1$ belong to one ligand, and S2 and P2 belong to the other.

The Pt-P2 distance in trans-1, corresponding to $\mathrm{PPh}_{3}$ is somewhat longer than the Pt-P1 distance corresponding to sarp (Fig. 3). The P-Pt-P angle is deformed ( $c a .172^{\circ}$ ) from linearity in trans-1 and cis-2, compared to symmetric trans-2 (Fig. 4, center of symmetry at Pt), owing to steric reasons. In trans-1, the hydride ligand has not been located but it must be placed trans 

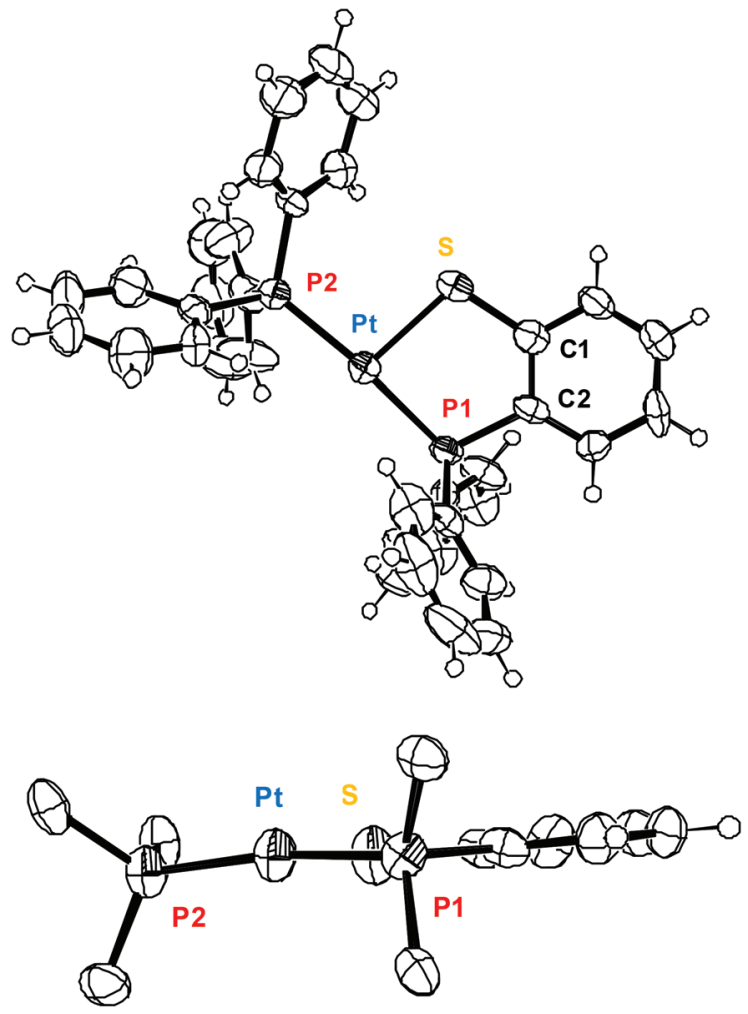

Fig. 3 ORTEP plots of trans-1, in the projection of the coordination plane parallel to the paper (above); the hydride ligand takes the position directly trans to the sulfur to complete the square-planar coordination of platinum(II); in the perpendicular projection (below) the phenyl rings of $-\mathrm{PPh}_{2}$ have been omitted for clarity (except for the ipso carbons).

to sulfur (NMR, IR), thus the $\mathrm{PPh}_{3}$ is somewhat displaced towards the smaller ligand. In the structures of 2 the sarp ligands are symmetrically disposed only in the trans isomer (Fig. 4), while in the cis isomer the P-Pt-P angle increases to $100.3(2)^{\circ}$ and the S-Pt-S angle decreases to $84.7(2)^{\circ}$ owing to the repulsion of the $-\mathrm{PPh}_{2}$ groups. The crystal structure of cis-1 could not be determined by XRD, but considering the structures of trans-1, trans-2 and cis-2, together with the spectroscopic data, leaves little doubt about its structure.

\section{Catalytic hydroformylation}

Complex trans-1 exhibits desirable characteristics for a homogeneous catalyst: it undergoes fast ligand exchange, it contains a hydride ligand susceptible to olefin insertion reactions and also triaryl phosphines which usually favor small molecule activation, and addition and elimination processes associated with homogeneous catalysis. However, ligand sarp is a sulfur donor and these ligands are often associated with catalyst deactivation rather than catalyst activation. ${ }^{20}$ The thiophilicity of late transition metals, coupled with the ability of thiolates to give one, two or even three electron pairs in terminal or bridged compounds respectively, ${ }^{21}$ may block catalytic activity in homogeneous systems, but this should not be the case here because of the presence of good competing ligands.
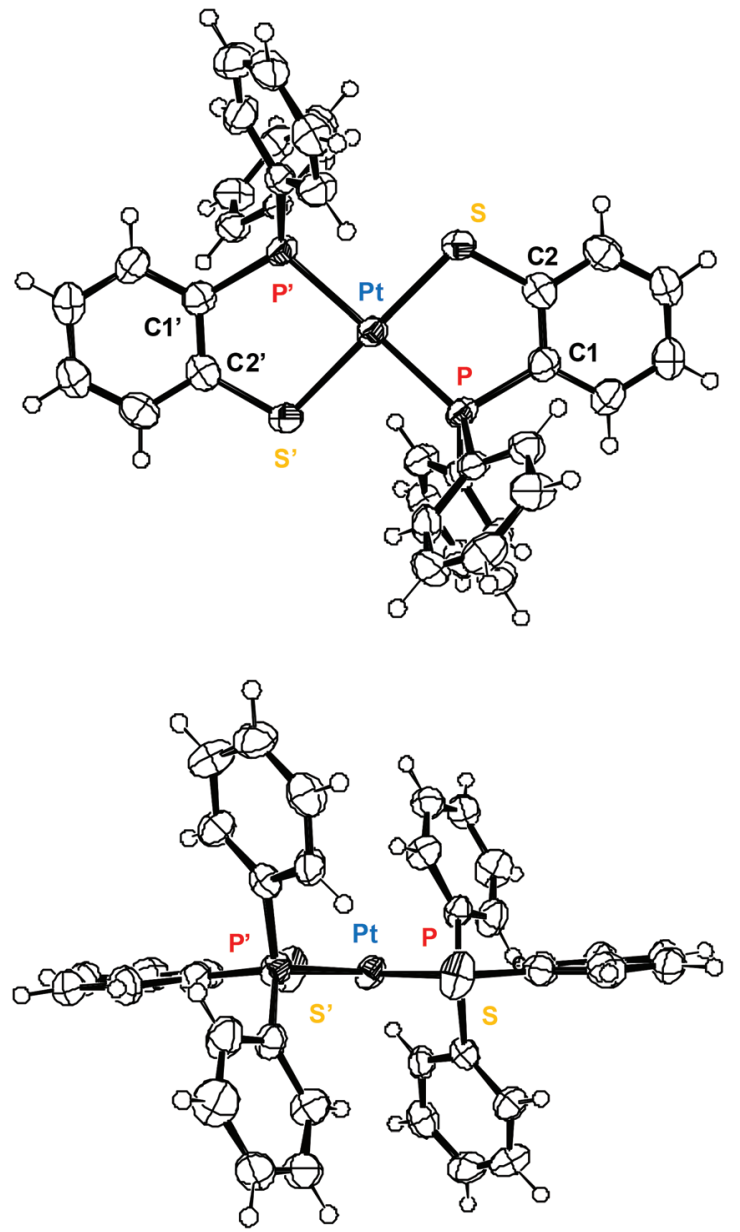

Fig. 4 ORTEP plots of trans-[Pt(sarp $\left.)_{2}\right]$, the platinum lies at a crystallographic inversion center, thus $\mathrm{P}^{\prime}$ and $\mathrm{S}^{\prime}$ are related to $\mathrm{P}$ and $\mathrm{S}$ by $-x,-y,-z$

Nevertheless, trans-1 was tested as a hydroformylation catalyst on styrene in the absence of tin, chloride or any other extra ligands. The first results were disappointing: no activity was detected with syngas pressures below 75 bar. At 75 bar and higher pressures the results were positive (Table 4), using styrene/platinum ratios of 400/1 conversions were essentially complete in $24 \mathrm{~h}$, with very low hydrogenation to ethylbenzene and a regioselectivity towards branched aldehyde of $c a .70 \%$. Lowering the styrene/platinum ratio it can be seen that average TON numbers are about 400 and TOF numbers around $18 \mathrm{~h}^{-1}$ (Table 4, entries 3 and 4). Selectivity increased somewhat upon increasing the hydrogen partial pressure (Table 4, entry 4). Complex cis-2 was identified in the reaction mixtures as one of the platinum products formed after the reaction was over (after all, it is the thermal decomposition product of trans-1). However, testing showed that cis-2 was not responsible for the previous results, as it turned out to perform very poorly, with residual activity and low selectivity (Table 4, entry 5). Instead of preformed trans-1, the mixture of $\mathrm{Pt}\left(\mathrm{PPh}_{3}\right)_{4}$ plus Hsarp was also tested with the above olefins, and found inactive; one reason for this could be the inherent presence of excess $\mathrm{PPh}_{3}$. 
Table 4 Hydroformylation of styrene with trans $-1^{a}$

\begin{tabular}{|c|c|c|c|c|c|c|c|}
\hline Catalyst & {$[\mathrm{S}] /[\mathrm{Pt}]$} & $P_{\mathrm{T}}^{b}$ & $t^{c}(\mathrm{~h})$ & $C^{d}(\%)$ & $\mathrm{TON}^{e}$ & $R^{f}(\%)$ & $H^{g}(\%)$ \\
\hline trans $-\mathbf{1}$ & 400 & 75 & 24 & 100 & 400 & 70 & 0.4 \\
\hline trans $-\mathbf{1}$ & 400 & 125 & 97 & 98 & 400 & 76 & 0.6 \\
\hline trans $\mathbf{- 1}$ & 900 & 125 & 24 & 48 & 432 & 66 & 1.2 \\
\hline trans-1 ${ }^{h}$ & 1000 & 100 & 24 & 46 & 460 & 84 & 0.9 \\
\hline$c i s-2$ & 400 & 75 & 24 & 5 & 20 & 58 & 0.2 \\
\hline
\end{tabular}

${ }^{a}$ Conditions: $19 \mathrm{mmol}$ styrene (S) in $20 \mathrm{~mL}$ toluene at $100{ }^{\circ} \mathrm{C} .{ }^{b}$ Total pressure (bar), $\mathrm{H}_{2} / \mathrm{CO}=1 .{ }^{c}$ Reaction time. ${ }^{d}$ Conversion of styrene to products. ${ }^{e}$ Average turnover number. ${ }^{f}$ Regioselectivity in iso-aldehyde. ${ }^{g}$ Hydrogenation product (ethylbenzene). ${ }^{h}$ In this experiment the pressure ratio $\mathrm{H}_{2} / \mathrm{CO}=1.3$.

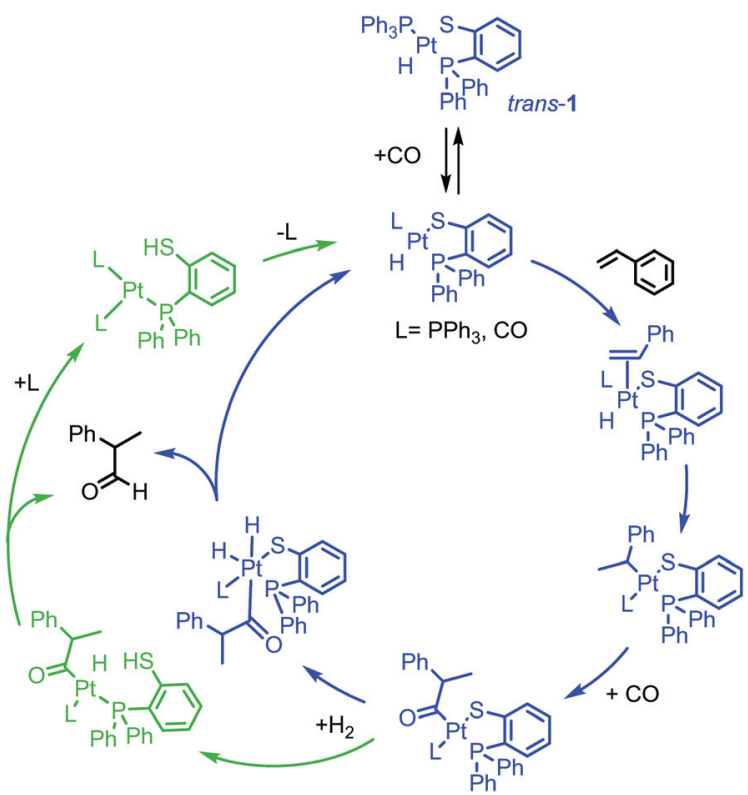

Scheme 5 Mechanistic proposal for hydroformylation with trans-1 as the catalyst.

We have drawn (Scheme 5) a working mechanism that could rationalize the activity of complex $\mathbf{1}$ (before more data available), which also considers the special characteristics of ligand sarp. The insertion of the olefin into the $\mathrm{Pt}-\mathrm{H}$ bond gives rise to an alkyl complex, which can be linear or branched, thus determining the regioselectivity of the reaction. It should be noted that for the branched alkyl, $\eta^{3}-\mathrm{C}_{8} \mathrm{H}_{9}$ coordination is possible, thus favoring both activity towards styrene and regioselectivity towards a branched product. It is very difficult to ascertain if $\mathrm{L}=\mathrm{PPh}_{3}$ or $\mathrm{CO}$ at this point (besides, the presence of $\mathrm{CO}$ in the coordination sphere of platinum does not even seem necessary until later). Insertion of $\mathrm{CO}$ causes the formation of the acyl complex which must react with hydrogen to yield the aldehyde and to regenerate the starting platinum species. For the activation of hydrogen by transition metal complexes, the first identified mechanism was oxidative addition, which would yield a platinum(Iv), $\mathrm{d}^{6}$, species (central path in Scheme 5, in blue). After the elimin- ation of the aldehyde, the cycle would be complete. However, given the nature of sarp (containing a proton-basic moiety not present in other ligands) we suggest that a different form of $\mathrm{H}_{2}$ activation can be considered (the lower path in Scheme 5, in green), with no need for oxidation of Pt(II) to Pt(Iv) in a reducing medium. This would be a heterolytic cleavage across the Pt-S bond, or hydogenolysis-type activation. A similar activation has been described for rhodium and iridium arylthiolates. ${ }^{22}$ Moreover, the activation of $\mathrm{H}_{2}$ to $\mathrm{Pt}-\mathrm{H}$ and $\mathrm{H}_{3} \mathrm{O}^{+}$(i.e. platinum mediated disproportionation of $\mathrm{H}_{2}$ to $\mathrm{H}^{-}$and $\mathrm{H}^{+}$) has been implicitly proposed in the context of the platinum catalyzed hydroformylation of styrene. ${ }^{23}$ In this mechanism the elimination of aldehyde gives a platinum(0) species that was already invoked in the synthetic part of this paper, and which we assume to readily react to form a platinum hydride and follow the cycle.

\section{Experimental}

Reactions were performed under nitrogen using standard techniques. ${ }^{24}$ The isolated products are fairly air stable, and hydride complexes were kept refrigerated. Solvents were dried, distilled under nitrogen, kept over molecular sieves and deaerated prior to use. ${ }^{25}$ Tetrakis(triphenylphosphine)platinum(0) was prepared by established procedures. ${ }^{26}$ The synthesis of the ligands Hsarp and Hsarp' have been described. ${ }^{27}$ NMR data are given on the $\delta$ scale and referenced in the usual manner. Catalysis experiments were performed in a stainless steel Autoclave Engineers EZE seal reactor of a standard vase (ca. $80 \mathrm{~mL}$ ) and cover design, mechanical stirring (magnetic drive), heating and temperature control through a thermocouple, and sample port. GC analyses were performed using capillary columns HP-5, $0.25 \mathrm{~mm}$ diameter $\times 30 \mathrm{~m}$ length, using FID and MS detectors. Elemental analyses (C, H and S) were performed with a Carlo Erba CHNS EA-1108. The platinum content was determined by repeated cycles of mineralization of a weighed sample with conc. $\mathrm{HNO}_{3}$ in a heated crucible (fume hood), followed by ignition in an electric furnace at temperatures over $900{ }^{\circ} \mathrm{C}$ (open crucible, $24 \mathrm{~h}$ ), this gave platinum metal that was weighed as such.

\section{$\mathrm{X}$-ray diffraction structure determination}

Data were collected using Mo K $\alpha$ radiation. For compounds trans-1 and cis-2. $\mathrm{CH}_{2} \mathrm{Cl}_{2}$ an Enraf-Nonius CAD4 diffractometer $\left(2 \theta_{\max }=50^{\circ}\right)$ was used; for compound trans-2, a Kuma KM4CCD $\left(2 \theta_{\max }=56^{\circ}\right)$ was used. Empirical absorption corrections were applied. Structures were solved by direct methods (SHELXS-86) and refined by full-matrix least-squares methods on $F^{2}$ for all reflections (SHELXL-97). Non-hydrogen atoms were refined anisotropically. Hydrogen atoms bonded to carbon atoms were placed in calculated positions with isotropic displacement parameters fixed at 1.2 times the $U_{\text {eq }}$ of the corresponding carbon atoms. In trans-1, the hydrogen bonded to the platinum atom was not localized in the difference Fourier map, and it has not been included in the refinement. 
Crystal data and further refinement details are presented as ESI. $\dagger$ Compound $c i s-\mathbf{2} \cdot \mathrm{CH}_{2} \mathrm{CL}_{2}$ is a solvate and some decay (caused by solvent loss) was observed during data collection; this may be the reason why in this structure high residual peaks (5.43 and -4.43 e $\AA^{-3}$ ) were found in the final difference density map, near to the Pt atom (1.05 $\AA$ and $1.12 \AA$ respectively).

Preparation of trans- $P, P-\left[\mathrm{PtH}\left(\operatorname{sarp}-\kappa^{2} P, S\right)\left(\mathrm{PPh}_{3}\right)\right]$ (trans-1), trans-P,P-hydrido[(2-diphenylphosphino)thiophenolato- $\left.\kappa^{2} P, S\right]$ triphenylphosphineplatinum(II). The platinum(0) complex $\mathrm{Pt}$ $\left(\mathrm{PPh}_{3}\right)_{4}$ (500 mg, $0.40 \mathrm{mmol}$ ) was dissolved in dichloromethane (ca. $30 \mathrm{~mL}$ ) to give a clear yellow solution, which was cooled down to $0{ }^{\circ} \mathrm{C}$. Upon slow addition of Hsarp (2-diphenylphosphino-thiophenol, $235 \mathrm{mg}, 0.80 \mathrm{mmol}$ dissolved in $5 \mathrm{~mL}$ of ethyl ether) to the ice-cold $\mathrm{Pt}\left(\mathrm{PPh}_{3}\right)_{4}$ solution, only partial loss of color was observed. The pale yellow solution was allowed to react for $10 \mathrm{~min}$ at room temperature and then its volume was reduced to $c a .1 \mathrm{~mL}$ under vacuum. Addition of ethyl ether $(3 \mathrm{~mL})$ and cooling to $0^{\circ} \mathrm{C}$ caused the precipitation of a yellow microcrystalline solid. The solution was kept cold for $1 \mathrm{~h}$ to allow for the full precipitation of the product. The solid was collected by filtration, washed with ether $(3 \times 5 \mathrm{~mL})$, and dried under vacuum. Yield: $248 \mathrm{mg}$ (83\%) of crude $\mathbf{1}$, microcrystalline and yellow in color. Data for crude 1: ${ }^{1} \mathrm{H}$ NMR (250 MHz, $\mathrm{CD}_{2} \mathrm{Cl}_{2}, 298 \mathrm{~K}$ ): $\delta-7.58$ (s, with ${ }^{195} \mathrm{Pt}$ satellites, $1 \mathrm{H}$, $\mathrm{H}-\mathrm{Pt}, J_{\mathrm{HPt}}=1023 \mathrm{~Hz}$ ); 6.8-7.4 (m, 29H arom.), unchanged down to $213 \mathrm{~K}$. This product was qualified as "crude" because, as prepared, it contained some $\mathrm{PPh}_{3}$ (from 0.5 to $1 \%$ depending on the sample) and some $\left[\mathrm{Pt}(\operatorname{sarp})_{2}\right]$ (from 0.1 to $1 \%$ ). Owing to the content in $\mathrm{PPh}_{3}$, the NMR spectra of crude 1 was always broad $\left({ }^{31} \mathrm{P}\right)$ or consistent with the fast-exchange limit $\left({ }^{1} \mathrm{H}\right)$. High purity trans-1 was obtained by column chromatography (over silica $60 \mathrm{~A}, 3 \mathrm{~cm}$ diameter, $40 \mathrm{~cm}$ length, diethyl ether/dichloromethane 90/10 eluent) or by slow crystallization. Procedure for crystallization: crude $\mathbf{1}(300 \mathrm{mg}$ ) was dissolved in dichloromethane $(60 \mathrm{~mL})$, the clear solution was filtered through a short column of Celite ( $1 \mathrm{~cm}$ diameter, $3 \mathrm{~cm}$ length) and poured into a clean, scratch-free flatbed crystallizer. The yellow solution was layered with ethyl ether $(10 \mathrm{~mL})$ and allowed to rest after being covered with a watch glass (under air). After $48 \mathrm{~h}$, the loss of volume caused by evaporation was made up with fresh ether ( $c a .30 \mathrm{~mL}$ ). After a further $72 \mathrm{~h}$ the solvent had evaporated completely. The residue consisted of large (ca. 1/16"-1/32") yellow pseudo-cubes of pure trans-1, a very small amount of small prismatic crystals of $\left[\operatorname{Pt}(\operatorname{sarp})_{2}\right]$ over a small amount of a fine white powder $\left(\mathrm{PPh}_{3}\right.$ and $\left.\mathrm{OPPh}_{3}\right)$, the recovery of pure trans $\mathbf{- 1}$ was above $90 \%$. Anal. Found: C, 57.01; H, 3.93; S, 4.42; Pt, 26.27. Calc. C, 57.52; H, 4.02; S, 4.27; Pt, 25.95. trans-1 was the only isomer present in the solid state or in freshly prepared solutions, cis-1 arose only with time and could not be isolated. The trans/cis equilibrium was reached in $24 \mathrm{~h}$, with a trans/cis ratio of $89 / 11$ in $\mathrm{CD}_{2} \mathrm{Cl}_{2}$, as measured by ${ }^{1} \mathrm{H}$ NMR. Data for pure 1: ${ }^{1} \mathrm{H}$ NMR $(250 \mathrm{MHz}$, $\mathrm{CD}_{2} \mathrm{Cl}_{2}, 298 \mathrm{~K}$ ) trans- $P, P$ isomer (major): $\delta-7.61$ (dd, with ${ }^{195} \mathrm{Pt}$ satellites, $1 \mathrm{H}, \mathrm{H}-\mathrm{Pt}, J_{\mathrm{HPt}}=1022.1 \mathrm{~Hz}, J_{\mathrm{PP}}=19.8 \mathrm{~Hz}, J_{\mathrm{PP}^{\prime}}=8.1$ $\mathrm{Hz}$ ); 6.8-7.4 (m, 29H arom.). cis- $P, P$ isomer (minor): $\delta-4.77$ (dd, with ${ }^{195} \mathrm{Pt}$ satellites, H-Pt, $J_{\mathrm{HPt}}=950 \mathrm{~Hz}, J_{\mathrm{PP}}=186 \mathrm{~Hz}$, $J_{\mathrm{PP}^{\prime}}=10 \mathrm{~Hz}$ ); 6.8-7.4 (m, 29H arom.). ${ }^{31} \mathrm{P}\left\{{ }^{1} \mathrm{H}\right\}$ NMR $(100 \mathrm{MHz}$, $\mathrm{CD}_{2} \mathrm{Cl}_{2}, 298 \mathrm{~K}$ ) trans- $P, P$ isomer (major): $\delta 31.9$ (d, with ${ }^{195} \mathrm{Pt}$ satellites, Pt-PPh $\left.{ }_{3}, J_{\mathrm{PPt}}=2915.2 \mathrm{~Hz}, J_{\mathrm{PP}}=391.2 \mathrm{~Hz}\right) ; 50.47(\mathrm{~d}$, with ${ }^{195} \mathrm{Pt}$ satellites, Pt-PPh $\mathrm{Ar}, J_{\mathrm{PPt}}=2818.6 \mathrm{~Hz}, J_{\mathrm{PP}}=391.2$ $\mathrm{Hz}$ ). cis- $P, P$ complex (minor): $\delta 24.3$ (d, with ${ }^{195} \mathrm{Pt}$ satellites, $\left.\mathrm{Pt}-\mathrm{PPh}_{3}, J_{\mathrm{PPt}}=3187 \mathrm{~Hz}, J_{\mathrm{PP}}=10.1 \mathrm{~Hz}\right) ; 56.6\left(\mathrm{~d}\right.$, with ${ }^{195} \mathrm{Pt}$ satellites, Pt-PPh $\left.2 \mathrm{Ar}, J_{\mathrm{PPt}}=1922 \mathrm{~Hz}, J_{\mathrm{PP}}=10.1 \mathrm{~Hz}\right)$. IR $(\mathrm{KBr}) \nu(\mathrm{Pt}-$ $\mathrm{H}): 2100 \mathrm{~cm}^{-1}$ (st). It was seen that the intensity of the $(\mathrm{Pt}-\mathrm{H})$ stretching, relative to the more intense ligand-originated vibration at $1569 \mathrm{~cm}^{-1}$, is a good qualitative measure of the contamination by $\mathrm{PPh}_{3}$ and [Pt(sarp $\left.)_{2}\right]$, for pure 1 the intensity ratio was $c a .0 .87$ on the transmittance scale.

Preparation of $\left[\mathbf{P t H}\left(\mathbf{s a r p}^{\prime}-\kappa^{2} P, S\right)\left(\mathbf{P P h}_{3}\right)\right]$ (3), hydrido[(2-diphenylphosphino)-6-trimethylsilylthiophenolato- $\left.\kappa^{2} P, S\right]$ triphenylphosphineplatinum(II). The platinum(0) complex $\mathrm{Pt}\left(\mathrm{PPh}_{3}\right)_{4}$ (300 $\mathrm{mg}, 0.24 \mathrm{mmol}$ ) was dissolved in dichloromethane (ca. $20 \mathrm{~mL}$ ) to give a clear yellow solution, which was cooled down to $0{ }^{\circ} \mathrm{C}$. Upon the slow addition of Hsarp' (134 mg, $0.36 \mathrm{mmol}$ dissolved in ca. $10 \mathrm{~mL}$ of ethyl ether) to the ice-cold $\mathrm{Pt}\left(\mathrm{PPh}_{3}\right)_{4}$ solution, only partial loss of color was observed. The pale yellow solution was allowed to react for $20 \mathrm{~min}$. at room temperature. The solvents were removed under vacuum and the resulting oily residue was stirred with $2 \mathrm{~mL}$ of cold ethyl ether (ice bath). This resulted in the formation of a pale yellow precipitate which was isolated by filtration and washed with a small amount (ca. $1 \mathrm{~mL}$ ) of diethyl ether, and dried under vacuum. Yield: $120 \mathrm{mg}(60 \%)$ of crude 3, yellow in color, complex 3 is much more soluble in common organic solvents than 1. Complex 3 thus obtained was contaminated with trace amounts of $\mathrm{PPh}_{3}$. Anal. Found: C, 56.49; H, 4.93; S, 3.53; Pt, 23.37. Calc. C, 56.85; H, 4.65; S, 3.89; Pt, 23.68. ${ }^{1} \mathrm{H}$ NMR $\left(250 \mathrm{MHz}, \mathrm{CDCl}_{3}, 298 \mathrm{~K}\right): \delta-7.08$ (d, with ${ }^{195} \mathrm{Pt}$ satellites, $1 \mathrm{H}$, $\left.\mathrm{H}-\mathrm{Pt}, J_{\mathrm{HPt}}=1151 \mathrm{~Hz}, J_{\mathrm{HP}}=6.6 \mathrm{~Hz}\right) ; 0.03\left(\mathrm{~s}, 9 \mathrm{H}, \mathrm{Si}\left(\mathrm{CH}_{3}\right)_{3}\right) ; 7.3$ (m, 28H, arom.). ${ }^{31} \mathrm{P}\left\{{ }^{1} \mathrm{H}\right\}$ NMR (101.3 MHz, $\left.\mathrm{CDCl}_{3}, 298 \mathrm{~K}\right): \delta$ 48.2 (s, with ${ }^{195} \mathrm{Pt}$ satellites, sarp', $\left.J_{\mathrm{PPt}}=2990 \mathrm{~Hz}\right)$. IR $(\mathrm{KBr})$ $\nu(\mathrm{Pt}-\mathrm{H}): 2068 \mathrm{~cm}^{-1}(\mathrm{~m})$.

Preparation of $\mathrm{EtSCH}_{2} \mathrm{CH}_{2} \mathrm{SH}$, 2-ethylthioethanethiol. A $100 \mathrm{~mL}$ side-arm flask was loaded with ethylene sulfide $\left(\mathrm{C}_{2} \mathrm{H}_{4} \mathrm{~S}, 3.0 \mathrm{~g}, 50 \mathrm{mmol}\right)$ dissolved in $60 \mathrm{~mL}$ of dry methanol and placed in an ice bath. To this, excess solution of potassium ethane thiolate (prepared by mixing $9.3 \mathrm{~g}$ of ethanethiol, $150 \mathrm{mmol}$, and $9.0 \mathrm{~g}$ of $85 \% \mathrm{KOH}, 137 \mathrm{mmol}$, in $60 \mathrm{~mL}$ of dry methanol) was slowly added. The mixture was allowed to warm up to room temperature and stirred for $1 \mathrm{~h}$. A solution of ammonium chloride ( $5.0 \mathrm{~g}, 93 \mathrm{mmol}$, in $40 \mathrm{~mL}$ of water) was added to quench the reaction, followed by drops of conc. $\mathrm{HCl}$ until acid to litmus. The precipitation of potassium chloride was observed at this point. The organic solvents were removed under vacuum. The $\mathrm{KCl}$ precipitate re-dissolved and oil separated, this oil was extracted with dichloromethane $(4 \times 10 \mathrm{~mL})$. The combined organic phases were dried with anhydrous magnesium sulfate. The solvent was removed at reduced pressure and the resulting oil was subjected to microdistillation at $3 \mathrm{~mm} \mathrm{Hg}$, the fraction was collected at $88-92{ }^{\circ} \mathrm{C}$. Yield: $3.78 \mathrm{~g}$ $(62 \%)$ of a colorless, malodorous, viscous liquid, $98 \%+$ by GC. 
${ }^{1} \mathrm{H}$ NMR (250 MHz, $\left.\mathrm{CDCl}_{3}, 298 \mathrm{~K}\right): \delta 1.26\left(\mathrm{t}, 3 \mathrm{H}, \mathrm{CH}_{3}, J_{\mathrm{HH}}=7.3\right.$ $\mathrm{Hz}$ ), 1.76 (second order $\mathrm{m}, 1 \mathrm{H},-\mathrm{SH}), 2.56\left(\mathrm{q}, 2 \mathrm{H},-\mathrm{CH}_{2}-, J_{\mathrm{HH}}=\right.$ $7.3 \mathrm{~Hz}$ ), 2.70-2.81 (second order $\mathrm{m}, 4 \mathrm{H},-\mathrm{CH}_{2} \mathrm{CH}_{2}-$ ). ${ }^{13} \mathrm{C}\left\{{ }^{1} \mathrm{H}\right\}$ NMR (62.5 MHz, $\left.\mathrm{CDCl}_{3}, 298 \mathrm{~K}\right): \delta 14.8$ (s), 24.7 (s), 25.8 (s), 35.7 (s). IR (liq. film, between $\mathrm{NaCl}$ crystals) $\nu(\mathrm{S}-\mathrm{H}): 2545 \mathrm{~cm}^{-1}$ (st).

Preparation of $\left[\mathrm{PtH}\left(\mathrm{EtSCH}_{2} \mathrm{CH}_{2} \mathrm{~S}-\kappa^{2} S, S\right)\left(\mathrm{PPh}_{3}\right)\right](4)$, hydrido (2-ethylthioethanethiolato- $\kappa^{2} S, S$ )triphenylphosphineplatinum(II). The platinum(0) complex $\mathrm{Pt}\left(\mathrm{PPh}_{3}\right)_{4}(200 \mathrm{mg}, 0.16 \mathrm{mmol})$ was dissolved in dichloromethane (ca. $20 \mathrm{~mL}$ ) to give a clear yellow solution. Upon addition of $\mathrm{EtSCH}_{2} \mathrm{CH}_{2} \mathrm{SH}$ (2-ethylthioethanethiol, $10 \mathrm{mg}, 0.16 \mathrm{mmol}$ ) loss of color was observed. It was allowed to react for $30 \mathrm{~min}$. and then the volume of the solution was reduced to $c a .2 \mathrm{~mL}$ under vacuum. Addition of $5 \mathrm{~mL}$ of ethyl ether and cooling to $0{ }^{\circ} \mathrm{C}$ caused the precipitation of a white powdery solid. The solution was kept cold for $1 \mathrm{~h}$ to allow for the full precipitation of the product. The solid was collected by filtration, washed with ether $(3 \times$ $2 \mathrm{~mL}$ ), and dried under vacuum. Yield: $81 \mathrm{mg}$ (87\%) of white powdery 4, soluble in $\mathrm{CH}_{2} \mathrm{Cl}_{2}$ and $\mathrm{CHCl}_{3}$, insoluble in $\mathrm{Et}_{2} \mathrm{O}$ and hexanes. Anal. Found: C, 45.26; H, 4.07; S, 10.81. Calc. C, 45.59; H, 4.35; S, 11.06. ${ }^{1} \mathrm{H}$ NMR (250 MHz, $\left.\mathrm{CDCl}_{3}, 298 \mathrm{~K}\right): \delta$ -10.63 (d, with ${ }^{195} \mathrm{Pt}$ satellites, ${ }^{1} \mathrm{H}, \mathrm{H}-\mathrm{Pt}, J_{\mathrm{HPt}}=1206 \mathrm{~Hz}, J_{\mathrm{HP}}=$ $20 \mathrm{~Hz}$ ); 0.83 (t, 3H, $\left.\mathrm{CH}_{3}, J_{\mathrm{HH}}=7.3\right) ; 1.95\left(\mathrm{~m} \mathrm{br}, 2 \mathrm{H}, \mathrm{CH}_{2} \mathrm{SPt}\right)$; 2.64 ( $\mathrm{m} \mathrm{br}, 2 \mathrm{H}, \mathrm{CH}_{2} \mathrm{SEt}$ ); 2.90 (m br, $2 \mathrm{H}, \mathrm{CH}_{2} \mathrm{Me}$ ); 7.3-7.6 (m, 15H, arom.). ${ }^{31} \mathrm{P}\left\{{ }^{1} \mathrm{H}\right\}$ NMR (101.3 $\left.\mathrm{MHz}, \mathrm{CDCl}_{3}, 298 \mathrm{~K}\right): \delta 23.65$ (s, with ${ }^{195} \mathrm{Pt}$ satellites, $\left.J_{\mathrm{PPt}}=3215 \mathrm{~Hz}\right) \cdot{ }^{13} \mathrm{C}\left\{{ }^{1} \mathrm{H}\right\}$ NMR (62.5 MHz, $\left.\mathrm{CDCl}_{3}, 298 \mathrm{~K}\right): \delta 13.9$ (s), 28.1 (s), 30.3 (s), 40.2 (s), 128.1-134.6 (m, arom.). IR (KBr) $\nu(\mathrm{Pt}-\mathrm{H}): 2111 \mathrm{~cm}^{-1}$ (st).

Preparation of $\left[\operatorname{Pt}\left(\operatorname{sarp}-\kappa^{2} P, S\right)_{2}\right]$ bis[(2-diphenylphosphino)thiophenolato- $\left.\kappa^{2} P, S\right]$ platinum(II) (2). The platinum(0) complex $\mathrm{Pt}\left(\mathrm{PPh}_{3}\right)_{4}$ (400 mg, $0.30 \mathrm{mmol}$ ) was dissolved in toluene (ca. $20 \mathrm{~mL}$ ) to give a yellow solution and Hsarp (2-diphenylphosphinothiophenol, $189 \mathrm{mg}, 0.60 \mathrm{mmol}$ ) was added. The pale yellow solution was heated to the reflux temperature (ca. $110^{\circ} \mathrm{C}$ ) and allowed to react until the Pt-H stretching absorption $\left(2100 \mathrm{~cm}^{-1}\right)$ was not detectable in the IR and the hydride signal was not seen in the ${ }^{1} \mathrm{H}$ NMR, which took a minimum of $28 \mathrm{~h}$. The volume was reduced to $c a .10 \mathrm{~mL}$ under vacuum. Cooling to $0{ }^{\circ} \mathrm{C}$ caused the start of crystallization. The solution was kept cold to allow for the full crystallization of the product. The solid was collected by filtration, washed with toluene $(3 \times 5 \mathrm{~mL})$, and dried under vacuum. Yield: $210 \mathrm{mg}$ (84\%) of 2 , microcrystalline and yellow in color. The crude product consists of a mixture of $c i s-P, P$ isomer (major product, ca. 95\%) and trans- $P, P$ isomer (minor product, ca. 5\%); crystals of the two isomers were collected for spectroscopic and single crystal analysis. Recrystallization of the crude material (it was simply dissolved in $150 \mathrm{~mL}$ of $\mathrm{CH}_{2} \mathrm{Cl}_{2}$, filtered and allowed to evaporate to dryness) gave cis- 2 free of any trans isomer $\left({ }^{31} \mathrm{P}\right.$ NMR). Anal. Found: C, 55.20; H, 3.46; S, 7.80; Pt, 25.17. Calc. C, 55.31; H, 3.61; S, 8.20; Pt, 24.96. Data for cis-2: ${ }^{1} \mathrm{H}$ NMR $\left(250 \mathrm{MHz}, \mathrm{CD}_{2} \mathrm{Cl}_{2}, 298 \mathrm{~K}\right): \delta$ 6.6-7.6 (m, Ar). ${ }^{31} \mathrm{P}\left\{{ }^{1} \mathrm{H}\right\} \mathrm{NMR}$ $\left(101.3 \mathrm{MHz}, \mathrm{CD}_{2} \mathrm{Cl}_{2}, 298 \mathrm{~K}\right) \delta 42.80$ (s, with ${ }^{195} \mathrm{Pt}$ satellites, $J_{\mathrm{PPt}}$ = $2912 \mathrm{~Hz}$ ). Data for trans-2: ${ }^{31} \mathrm{P}\left\{{ }^{1} \mathrm{H}\right\} \mathrm{NMR}\left(101.3 \mathrm{MHz}, \mathrm{CD}_{2} \mathrm{Cl}_{2}\right.$, $298 \mathrm{~K}) \delta 50.80$ (s, with ${ }^{195} \mathrm{Pt}$ satellites, $\left.J_{\mathrm{PPt}}=2645 \mathrm{~Hz}\right)$.
Preparation of $\left[\mathrm{Pt}\left(\operatorname{sarp}^{\prime}-\kappa^{2} P, S\right)_{2}\right](5)$, bis[(2-diphenylphosphino)-6-trimethylsilylthiophenolato- $\left.\kappa^{2} P, S\right]$ platinum(II). The platinum(0) complex $\mathrm{Pt}\left(\mathrm{PPh}_{3}\right)_{4}(400 \mathrm{mg}, 0.30 \mathrm{mmol})$ was dissolved in toluene $(c a .20 \mathrm{~mL})$ to give a yellow solution and Hsarp' (234 mg, $0.60 \mathrm{mmol}$, dissolved in $10 \mathrm{~mL}$ of toluene) was added. The pale yellow solution was heated to the reflux temperature $\left(\mathrm{ca} \cdot 110^{\circ} \mathrm{C}\right.$ ) and allowed to react until the $\mathrm{Pt}-\mathrm{H}$ stretching absorption $\left(2068 \mathrm{~cm}^{-1}\right)$ was not detectable in the IR and the hydride signal was not seen in the ${ }^{1} \mathrm{H}$ NMR, which took a minimum of $28 \mathrm{~h}$. The solvent was removed under vacuum and the oily residue was stirred with $20 \mathrm{~mL}$ of ethyl ether at $0{ }^{\circ} \mathrm{C}$ (ice bath). The solid that formed was isolated by filtration, washed with cold ethyl ether $(2 \times 4 \mathrm{~mL})$ and vacuum dried. Yield: $162 \mathrm{mg}$ (55\%) of 5, yellow in color. This material was found to be a mixture of cis- $P, P$ and trans- $P, P$ isomers (ca. 45/55). Anal. Found: C, 54.56; H, 4.81; S, 6.63. Calc. C, 54.47; H, 4.79; S, 6.92. Data for cis-5: ${ }^{1} \mathrm{H}$ NMR $(250 \mathrm{MHz}$, $\left.\mathrm{CDCl}_{3}, 298 \mathrm{~K}\right): \delta 0.24$ (s, 9H, $\left.\mathrm{Si}\left(\mathrm{CH}_{3}\right)_{3}\right) ; 6.6-7.7$ (m, 13H, arom). ${ }^{31} \mathrm{P}\left\{{ }^{1} \mathrm{H}\right\}$ NMR (101.3 MHz, $\left.\mathrm{CDCl}_{3}, 298 \mathrm{~K}\right) \delta 41.90$ (s, with ${ }^{195} \mathrm{Pt}$ satellites, $\left.J_{\mathrm{PPt}}=2867 \mathrm{~Hz}\right)$. Data for trans-5: ${ }^{1} \mathrm{H}$ NMR $(250 \mathrm{MHz}$, $\left.\mathrm{CDCl}_{3}, 298 \mathrm{~K}\right): \delta 0.39$ (s, 9H, $\left.\mathrm{Si}\left(\mathrm{CH}_{3}\right)_{3}\right) ; 6.6-7.7$ (m, 13H, arom). ${ }^{31} \mathrm{P}\left\{{ }^{1} \mathrm{H}\right\}$ NMR (101.3 MHz, $\left.\mathrm{CDCl}_{3}, 298 \mathrm{~K}\right) \delta 48.90$ (s, with ${ }^{195} \mathrm{Pt}$ satellites, $\left.J_{\mathrm{PPt}}=2629 \mathrm{~Hz}\right)$.

\section{Hydroformylation experiments}

The reactor was conditioned by vacuum and syngas replenishment cycles. The reaction mixture was injected into the reactor through an inlet valve (followed by some fresh solvent in order to clean the valve) at room temperature and the pressure was set to about 30 bar. The temperature was raised to working temperature using the temperature regulator and then the pressure was adjusted to working pressure through the gas supply system. The mechanical stirring was initiated $\left(400 \mathrm{~s}^{-1}\right)$ and this was considered time zero. The reaction mixture consisted of, typically, the alkene (in the case of styrene, $2.00 \mathrm{~g}$, $0.0192 \mathrm{~mol})$, complex $1\left(0.0364 \mathrm{~g}, 4.75 \times 10^{-5} \mathrm{~mol}\right.$; this value depends on the entry in Table 4$)$ and toluene $(20 \mathrm{~mL}$ total solvent). The organic products were analyzed by GC and NMR. Blank experiments under the conditions of Table 4 run without complex 1 added or with $\mathrm{PPh}_{3}$ added instead of complex $1(0.02-0.20 \mathrm{~g})$ gave no conversion. Out of the reactor all solutions were homogeneous and yellow in color with no black platinum or other precipitates. After some time, the formation of some crystals was generally observed; they were identified as cis-2.

\section{Conclusions}

Ligands Hsarp and Hsarp' readily reacted with $\mathrm{Pt}\left(\mathrm{PPh}_{3}\right)_{4}$ to give hydride complexes trans-[PtH(sarp) $\left.\left(\mathrm{PPh}_{3}\right)\right]$. The yield of 1 depends mainly on the stoichiometry employed, an excess of Hsarp being necessary for good yields. This does not seem to be a kinetic effect as yields are not influenced by the reaction time or temperature. This dependence is ascribed to an equilibrium in the chelate-assisted oxidative addition of ArS-H to Pt 
(0). The crude also contains very small amounts of cis-[PtH(sarp) $\left.\left(\mathrm{PPh}_{3}\right)\right]$, cis-[Pt(sarp) $\left.\left.)_{2}\right)\right]$ and $\mathrm{PPh}_{3}$. Under these conditions the trans- $P, P$ hydride undergoes very fast exchange of coordinated $\mathrm{PPh}_{3}$ with free $\mathrm{PPh}_{3}$ and has very broad signals in the NMR, while the cis- $P, P$ hydride exhibits narrow signals at the same temperature, which means that it does not undergo fast $\mathrm{PPh}_{3}$ exchange. These hydrides are remarkably stable towards oxygen and moisture, which allowed purification by column chromatography. Pure trans-1 does not show any broadness in the NMR; the addition of free $\mathrm{PPh}_{3}$ shows that the exchange of $\mathrm{PPh}_{3}$ is bimolecular. Only trans-1 is isolated as solid crystals upon recrystallisation, fresh solutions show the signals of trans-1 only, but with time the cis isomer becomes apparent. Equilibrium was reached in $24 \mathrm{~h}$ and the solution contained $89 \%$ trans-1 and $11 \%$ cis-1. Fast exchange and trans/cis equilibrium was not observed in other non-sarp containing complexes such as 4 . The reaction of $\mathrm{Pt}\left(\mathrm{PPh}_{3}\right)_{4}$ or 1 with excess Hsarp (at $110 \mathrm{C}, 24 \mathrm{~h}$ ) yields bischelates [Pt(sarp) $)_{2}$, the cis isomer being more stable thermodynamically. In ${ }^{31} \mathrm{P}$ NMR, cis-2 shows a signal at $\delta 42.80$ with ${ }^{195} \mathrm{Pt}$ satellites $\left({ }^{1} J_{\mathrm{PtP}}=\right.$ $2912 \mathrm{~Hz})$ and trans-2 shows a signal at $\delta 50.80\left({ }^{1} J_{\mathrm{PtP}}=2645 \mathrm{~Hz}\right)$ which is in agreement with XRD results and with the general observation that direct $\mathrm{Pt}-\mathrm{P}$ coupling constants are larger for cis- $P, P$ isomers.

Hydride complex trans-1 was found worth evaluating as a hydroformylation catalyst but was found inactive at low pressures. At higher pressures, however, it was found active on styrene. The activity of trans $\mathbf{- 1}$ is comparable to platinum/ diphosphine/ $\mathrm{SnCl}_{2}$ systems published recently, ${ }^{28}$ but its selectivity is different. This difference in selectivity would support trans-1 as a new catalytic system.

\section{Acknowledgements}

This work was financially supported by the Direccion General de Enseñanza Superior e Investigación Cientifica (DGESIC) of Spain though project BQU2002-04070-C02.

\section{Notes and references}

1 (a) J. R. Dilworth and N. Wheatley, Coord. Chem. Rev., 2000, 199, 89-158; (b) D. K. Dutta and B. Deb, Coord. Chem. Rev., 2011, 255, 1686-1712.

2 (a) P. W. N. M. van Leeuwen, Homogeneous Catalysis: Understanding the Art, Kluwer AP, Dordrecht (The Netherlands), 2004, p. 122 and references therein; (b) N. Brugat, A. Polo, A. Álvarez-Larena, J. F. Piniella and J. Real, Inorg. Chem., 1999, 38, 4829-4837.

3 (a) J. S. Kim, J. H. Reibenspies and M. Y. Darensbourg, J. Am. Chem. Soc., 1996, 118, 4115-4423; (b) C. A. Grapperhaus, K. B. Venna and M. S. Mashuta, Inorg. Chem., 2007, 46, 8044-8050.

4 H. Kuniyasu, F. Yamashita, T. Hirai, J.-H. Ye, S.-I. Fujiwara and N. Kambe, Organometallics, 2006, 25, 566-570.
5 L.-P. He, M. Hong, B.-X. Li, J.-Y. Liu and Y.-S. Li, Polymer, 2010, 51, 4336-4339.

6 (a) R. J. Angelici, Organometallics, 2001, 20, 1259-1275; (b) D. A. Vicic and W. D. Jones, J. Am. Chem. Soc., 1999, 121, 7606-7617.

7 (a) P. V. Rao, S. Bhaduri, J. Jiang, D. Hong and R. H. Holm, J. Am. Chem. Soc., 2005, 127, 1933-1945; (b) S. Ye, F. Neese, A. Ozarowski, D. Smirnov, J. Krzystek, J. Telser, J.-H. Liao, C.-H. Hung, W.-C. Chu, Y.-F. Tsai, R.-C. Wang, K.-Y. Chen and H.-F. Hsu, Inorg. Chem., 2010, 49, 977-988; (c) T.-W. Chiou and W.-F. Liaw, Inorg. Chem., 2008, 47, 7908-7913; (d) C.-M. L. Lee, Y.-L. Chuang, C.-Y. Chiang, G.-H. Lee and W.-F. Liaw, Inorg. Chem., 2006, 45, 1089510904; (e) T. Ohkubo, H. Sakashita, T. Sakuma, M. Kainosho, M. Sekiguchi and K. Morikawa, J. Am. Chem. Soc., 1994, 116, 6035-6036; (f) L. C. Myers, M. P. Terranova, A. E. Ferentz, G. Wagner and G. L. Verdine, Science, 1993, 261, 1164-1167.

8 N. Salvarese, N. Morellato, A. Venzo, F. Refosco, A. Dolmella and C. Bolzati, Inorg. Chem., 2013, 52, 63656377.

9 (a) Rhodium Catalyzed Hydroformylation, ed. P. W. N. M. van Leeuwen and C. Claver, Kluwer, Dordrecht (The Netherlands), 2000; (b) R. Franke, D. Selent and A. Borner, Chem. Rev., 2012, 112, 5675-5732; (c) E. V. Gusevskaya, J. JiménezPinto and A. Börner, ChemCatChem, 2014, 6, 382-411.

10 (a) J. Pospech, I. Fleischer, R. Franke, S. Buchholz and M. Beller, Angew. Chem., Int. Ed., 2013, 52, 2852-2872. See also: (b) C. Kubis, W. Baumann, E. Barsch, D. Selent, M. Sawall, R. Ludwig, K. Neymeyr, D. Hess, R. Franke and A. Börner, ACS Catal., 2014, 4, 2097-2108.

11 (a) A. Haynes, P. M. Maitlis, G. E. Morris, G. J. Sunley, H. Adams, P. W. Badger, C. M. Bowers, D. B. Cook, P. I. E. Elliott, T. Ghaffar, H. Green, T. R. Griffin, M. Payne, J. M. Pearson, M. J. Taylor, P. W. Vickers and R. J. Watt, J. Am. Chem. Soc., 2004, 126, 2847-2861, and references therein. (b) G. J. Sunley and D. J. Watson, Catal. Today, 2000, 58, 293-307; (c) J. H. Jones, Platinum Met. Rev., 2000, 44, 94-105; (d) J. Hartwig, Organotransition Metal Chemistry: From Bonding to Catalysis, University Science Books, Sausalito CA, 2010, p. 749. ISBN 978-1-891389-53-5.

12 (a) J. Duran, A. Polo, J. Real, J. Benet-Buchholz, A. Poater and M. Solà, Eur. J. Inorg. Chem., 2003, 4147-4151; (b) J. Duran, N. Brugat, A. Polo, J. Real, X. Fontrodona and J. Benet-Buchholz, Organometallics, 2003, 22, 3432-3438; (c) N. Brugat, J. Duran, A. Polo, J. Real, A. Álvarez-Larena and J. F. Piniella, Tetrahedron: Asymmetry, 2002, 13, 569577.

13 L. Jánosi, T. Kégl and L. Kollár, J. Organomet. Chem., 2008, 693, 1127-1135.

14 J. Duran, A. Polo, J. Real, J. Benet-Buchholz, M. Solà and A. Poater, ChemistryOpen, 2016, DOI: 10.1002/open.201500136. 15 R. G. Pearson, Inorg. Chem., 1973, 12, 712-713.

16 (a) J. Real, E. Prat, A. Polo, A. Alvarez-Larena and J. F. Piniella, Inorg. Chem. Commun., 2000, 3, 221; (b) D. Canseco-González, S. Gómez-Benítez, S. Hernández- 
Ortega, R. A. Toscano and D. Morales-Morales, J. Organomet. Chem., 2003, 679, 101-109.

17 T. B. Rauchfuss and D. M. Roundhill, J. Am. Chem. Soc., 1975, 97, 3386-3392.

18 (a) P. E. Garrou, Chem. Rev., 1981, 81, 229; (b) O. Kühl, Phosphorus-31 NMR Spectroscopy, Springer, 2008, ISBN 9783-540-79117-1; (c) Prosphorus-31 NMR Spectroscopy in Stereochemical Analysis, ed. J. G. Verkade and L. D. Quin, VCH, 1987, ISBN 0-89573-149-5; (d) Phosphorus-31 NMR, Principles and Applications, ed. D. G. Gorenstein, Academic Press, 1984, ISBN 0-12-291750-2; (e) S. O. Grim, R. L. Keitler and W. McFarlane, Inorg. Chem., 1967, 6, 1133-1137.

19 (a) R. S. Paonesa and W. C. Trogler, J. Am. Chem. Soc., 1982, 104, 1138-1040; (b) R. S. Paonesa and W. C. Trogler, Inorg. Chem., 1983, 22, 1038-1048; (c) R. H. Reamey and G. M. Whitesides, J. Am. Chem. Soc., 1984, 106, 81-85; (d) P. S. Pregosin and H. Rügger, Inorg. Chim. Acta, 1984, 86, 55-60. See also: (e) O. J. Scherer and H. Jungman, J. Organomet. Chem., 1981, 208, 153-159; (f) P. S. Pregosin, R. Favez, R. Roulet, T. Boschi, R. A. Michelin and R. Pos, Inorg. Chim. Acta, 1980, 45, L7-L9.

20 Poisoning by sulfur is common in heterogeneous, supported metal catalysts that contain highly dispersed metal atoms, clusters, or larger "rafts" or crystallites with no ligands, thus coordinatively unsaturated, and tend to abstract sulfur from sulfur containing impurities in the gas flow and form layers of metal sulfide that block the reactive sites. See, for instance: B. C. Gates, Catalytic Chemistry, Wiley, New York, 1992, p. 352. ISBN 0-47155914-8.

21 A. Polo and J. Real, in Houben-Weyl Science of Synthesis, ed. N. Kambe, Thieme, New York, 2008, vol. 39, p. 437, ISBN 978-1-58890-530-7.

22 (a) Y. Ohki, M. Sakamoto and K. Tatsumi, J. Am. Chem. Soc., 2008, 130, 11610-11611; (b) M. Sakamoto, Y. Ohki, G. Kehr, G. Erker and K. Tatsumi, J. Organomet. Chem., 2009, 694, 2820-2824.

23 M. Gottardo, A. Scarso, S. Paganelli and G. Strukul, Adv. Synth. Catal., 2010, 352, 2251-2262. See page 2260, Scheme 4.

24 D. F. Shriver and M. A. Drezdzon, The Manipulation of Air Sensitive Compounds, Wiley-Interscience, New York, 2nd edn, 1986, ISBN 0-471-86773-X.

25 D. D. Perrin, W. L. F. Armarego and D. R. Perrin, Purification of Laboratory Chemicals, Pergamon Press, Oxford, 3rd edn, 1988, ISBN 0-08-034714-2.

26 R. Ugo, F. Cariati and G. LaMonica, Inorg. Synth., 1968, 11, 105.

27 (a) E. Block, G. Ofori-Okai and J. Zubieta, J. Am. Chem. Soc., 1989, 111, 2327; (b) E. Block, V. Eswarakrishnan, M. Gernon, G. Ofori-Okai, C. Saha, K. Tang and J. Zubieta, J. Am. Chem. Soc., 1989, 111, 658.

28 P. Pongrácz, L. Kollár and L. T. Mika, Green Chem., 2016, DOI: 10.1039/c5gc01778e, in press. 